\title{
A Hermeneutic Interpretation of Concepts in a Cooperative Multicultural Working Project
}

\author{
Prof. Dr. Ursula Kirschner \\ Leuphana University Lüneburg, Germany \\ kirschner@uni.leuphana.de
}

\begin{abstract}
What are frontier zones in contemporary urban cities? This research project was developed in cooperation with an interdisciplinary group of researchers and students from Brazil and Germany and launched with an International Summer School in São Paulo in 2015. Its aim was to explore and invent urban spaces using the method of documentary film making as a medium to provide new insights and readings of the contemporary city. In Germany we analyzed these film productions by examining the main topics of the frontier zones in São Paulo. The method of documentary film making was once again chosen for the hermeneutic interpretation.
\end{abstract}

Keywords: perception of space; documentary film making; hermeneutic analysis

\section{Introduction}

The research project on "Frontier Zones" was developed in cooperation with an interdisciplinary group of researchers and students from Brazil and Germany. For 14 days in 2015 about 30 researchers, including architects, city planers, film makers, journalists, audio experts, social scientists and sociologists, met in São Paulo to work and discuss how to explore the city. The method was strongly collaborative, working with students and teachers as well as with the people we filmed on the streets of São Paulo. There is no neutral observer, only authors with different cultural and personal backgrounds.

At Leuphana University in Germany in a context of one seminar we studied the produced Brazilian films from 2015. All students never have been in South America. We selected key sequences of the Brazilian films and asked ourselves which kind of frontier zone we see, how they are visualized, and how sound interacts with the images. We used the hermeneutic interpretation and again applied the method of documentary film making. The greatest challenge was looking at who the same protagonists are in Germany and finding out which places have similar situations, which at the same time helped all of the participants better understand the situations in São Paulo. The purpose of this paper is to provide a methodology for analyzing urban space.

\section{What are Frontier Zones?}

The first approach to determining what kind of frontier zones you wish to analyze is to think about space. A built environment is ambiguous - in physics "space" is related to fields, while in mathematics "spaces" are understood to be sets of points. (Janich, 1973) This philosophy has a lot of spatial theory, e.g. Aristotles uses the term Topos as a synonym for places. Topos provides space. Topos is not determined by borders but by objects and people. In urban areas, geometric spaces such as constructed interiors and exteriors, roads, squares, etc. along with dynamic spaces such as political, social, societal, capitalistic, etc. spaces, form the urban space that we refer to as frontier zones. In this sense, "Space is not static. It emerges from the vivid, corporal orientation of humans and the world." (Hauser, 2011)

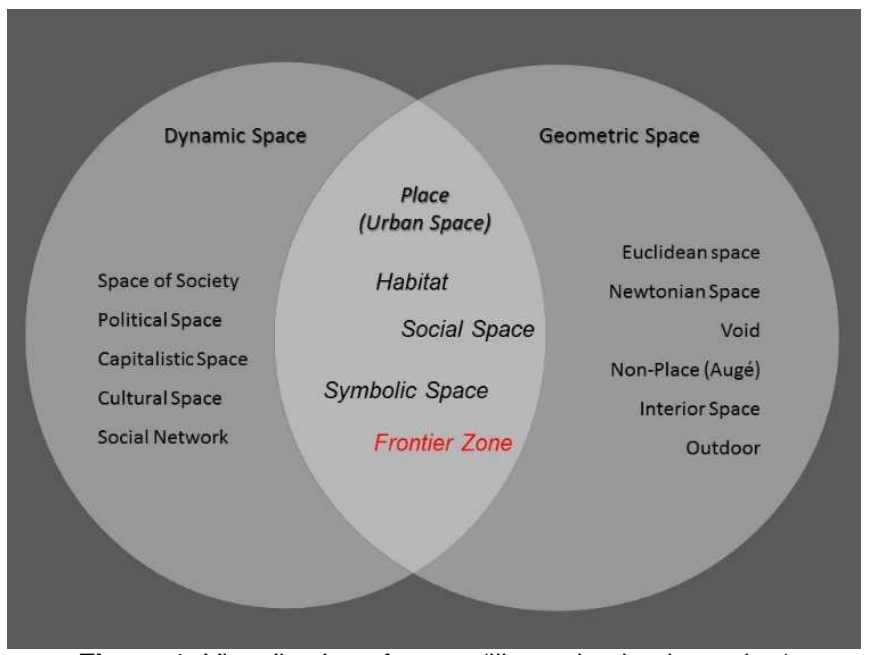

Figure 1: Visualization of space (illustration by the author)

\section{Why is Film Making the Best Way to Document Frontier Zones?}

Discovering "frontier zones" in urban areas and examining them from a variety of perspectives applying the language of documentary film making as an exploratory way to analyze urban areas is based on the thesis posed by the media scientists Horwitz, Joerges and Potthast (1996). They propose that, through the use of images, film allows one to get "closer" to social realities than would be possible with text-based empirical social research.

Film has always been an ideal way to obtain an overview of the transformational forces of urban development. If one thinks of space as motion in time, "In space we read the time" (Schlögel, 2009), this correlation becomes tangible. After all, film is also founded on motion in time. Even the first films 
created by the Lumières (laborers leaving the factory or a train arriving at the station) had as a foundation the notion of progress. And at the very latest, the city itself became the protagonist of a film with Ruttmann's "Berlin - Symphony of a Great City."

In addition to the important research and archiving aspect, the concept of an audio-visual documentary narration of urbanity provides the critical potential to visualize and examine current urban developments, and the results should have an impact on future planning. It also reinforces the value of local actors in a "global city," applying affordable digital production media.

\section{Idea of Film Documentary}

The objective of the documentaries was to obtain results that could not be communicated merely with words. The captured sound and images in the city were used to convey the frontier zones. The main rule for the focus of an audio-visual documentation without using language as the means to convey information is founded on the language interpretation of transcultural communication. It is firmly linked to the interculturality - the relationships that exist between the different cultures. Entering into a transcultural dialog with a documentary film means facilitating communication between people and overcoming false interpretations of the group's language symbols and impressions of the environment that already have other meanings. Reciprocally, it is perceived as foreign when, in communication, codes are encountered that seem strange to one's own (language) conventions.

The following section calls on Francois Julliens' (2009) criticism of the dialog between the cultures to analyze the extent to which the audio-visual documentary film represents a transcultural dialog.

Jullien calls the dialog between the cultures "weak" and "hypocritical" and talks about an imbalance, because the dialog is "[...] distinguished by power relationships and indirect strategies [...]." (p.194f.) A successful dialog is possible only with a balance of power. However, Jullien concludes that this is not possible because language itself creates a relationship between the different cultures of disproportionate power. Jullien states that, when communication of the dialog occurs in the language of one of the two partners, this creates an "imbalance" between the conversation partners right from the start.

Jullien also rejects communication in a third language. Every language has its own logic and works according to its own thought patterns: "[...] Under the pretense of offering itself as a medium, it forces itself upon one." (p.195) A communication deficit would be an example of this. We chose English as the project language for communication amongst the Brazilian and German scientists. When we attempted to translate the object of our research -"Grenzzonen" in German, "zona de fronteiras" in Portuguese - we encountered multiple terms that describe the same or similar objects, such as "frontier zones," "boundary zones," "border zones" and "limits."

This is why, in the documentary, language is used as music and not as a means to convey information. "Foreign" can be perceived in such vastly different ways: as being from a different country, as something strange and abnormal, as something not yet known, as unrecognizable, or as something scary and unfamiliar.

\section{Different Frontier Zones in São Paulo}

São Paulo is a portrait of Brazilian society, with an impressive mix of diverse cultural backgrounds. It was characterized by the hundreds of thousands of people coming to Brazil from around the world seeking work at the coffee plantations at the end of the 19th century.

Life in the São Paulo of today is a multi-faceted experience. From a sociological point of view, Brazil's primary financial center is a fragmented place, an urban patchwork in which the rich live far removed from the poor in many different ways. From the geographic, historic center, where the city was founded by Portuguese Jesuits in 1554, to the impoverished outreaches of the urban sprawl, one finds a vast range of urban habitats. In each of four groups, different film ideas were developed for various locations along the oldest underground train line in São Paulo, from Tucuruvi to Jabáquara.

Film no. 1 deals with the culture of remembering historical events in a certain place, the event being the massacre in the Carandigru prison and the contemporary repurposing of the area after the prison buildings were torn down to create a park with a design college and a library. The ethnologist Victor Turner stated that the event as a frontier could be described as a liminal period. Therefore the film attempts to likewise convey the atmosphere of the preliminal period in the subsequent use - the postliminal phase. Richard Rohr (2017) describes it as, "... It is when you have left the tried and true, but have not yet been able to replace it with anything else. It is when you are between your old comfort zone and any possible new answer. If you are not trained in how to hold anxiety, how to live with ambiguity, how to entrust and wait, you will run...anything to flee this terrible cloud of unknowing."

Film no. 2 addresses informal and formal commerce in the public space, and at the same time it examines the common zones and intersecting paths. The conflict arises from the meeting of the illegal sphere and the real market.

Film no. 3 looks at the time of sunrise and sunset as a period in which certain people ready the city to meet the day. And it regards a favela, situated in the shadow of urban high rises but inhabited by a different society. Light is an essential atmospheric determinant in both cases.

Film no. 4 attempts to capture the marginalization from the city society of different ethnic groups, with their cultural identity and various social classes. Close-up shots give emotion to marginalization as a frontier zone.

All four of the films examine the atmosphere - the temporal, spatial, social and economic atmosphere. Gernot Böhme (2013) describes atmospheres as "tempered rooms" or as "spatially extended, quasi objective sentiments" (p.16) that 
convey the objective qualities of an environment with the bodily-sensual states of a person in this environment. (p. 26) He promotes the thesis that perception of atmospheres is not dependent only of people's inner moods. It is more objective and is dominant in the sense that it is similar for several people at the same time and place. As an example, he states that watching a storm is perceived similarly by all observers. These atmospheres influence feelings of people in a room, which in turn influence their perception and potentially their behavior. (p. 25 f.)

\section{Hermeneutic Interpretation - A Methodology}

The core of the basic methodological framework of hermeneutic sociology of knowledge expresses "The comprehension, meaning the process with which experiences are given meaning. It assumes ordinary comprehension, which includes understanding of self and others." (Herbrik, 2016, p.5)The resulting oscillation between the truth and potential of the depicted situation leads to an awareness of the existing reality. "Thus people learn to understand themselves by learning how others understand them." (p. 5)

At the beginning of a sequence analysis, a group of students compiles different ways of reading and interpreting a sequence and looks at different aspects thereof. Deceleration and dissociation are an essential methodical tool. Then another sequence is added to generate new interpretations and eliminate others. This progression is intended to take the wealth of possible interpretations gathered at the start and reduce to a minimum the potential ways that they can be perceived.

The produced films were used for a hermeneutic sequence analysis by applying what is seen to a different urban context, thus obtaining insights into the initial place and the new place - or into frontier zones in large cities.

"...[The hermeneutics of knowledge] provide all of the conditions essential to interdisciplinary [and intercultural] interpretation of, understanding of and reflection on the contents as well as the processes of understanding.

"According to Herbrik, the approach to a sequence analysis ... can be summarized based on these steps:

\section{Specification of a sequence and then of its context}

\section{Development of interpretations and variations}

\section{Development of potential connections}

4. Consulting another sequence and possibly the context, examination of the interpretations, development of additional interpretations and variations; repetition of this step until the scope of interpretations is satisfactory.

5. Summary of the specific nature of the case and generalization"
The different interpretations of city and the development of variations or transference to other urban spaces, in our case in an international comparison, enable general statements on "frontier zones" in large cities to be made. New viewpoints open up new spaces, while at the same time spheres of activity are compared, leading to new insights.

\section{Case Study}

This case study will focus on a few sequences from some films.

First from No. 2, called "Sampaths."

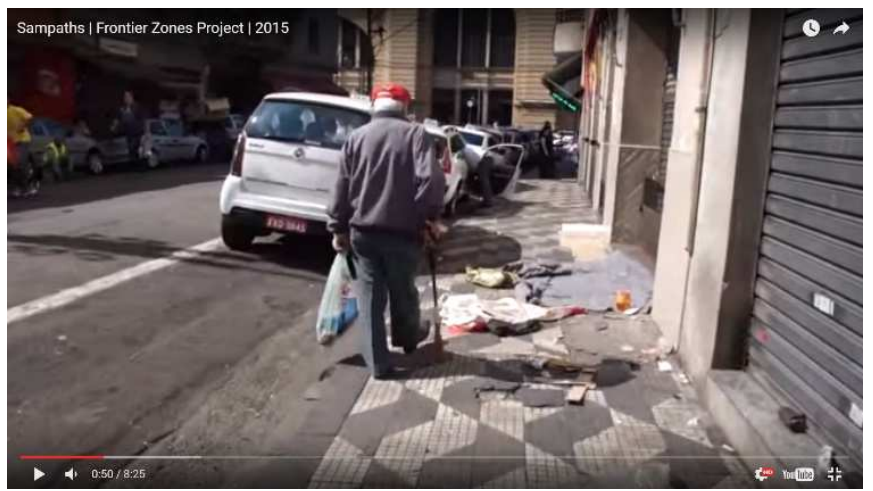

Figure 2: Appropriation of space, place to sleep, protagonist; sequence 0:50

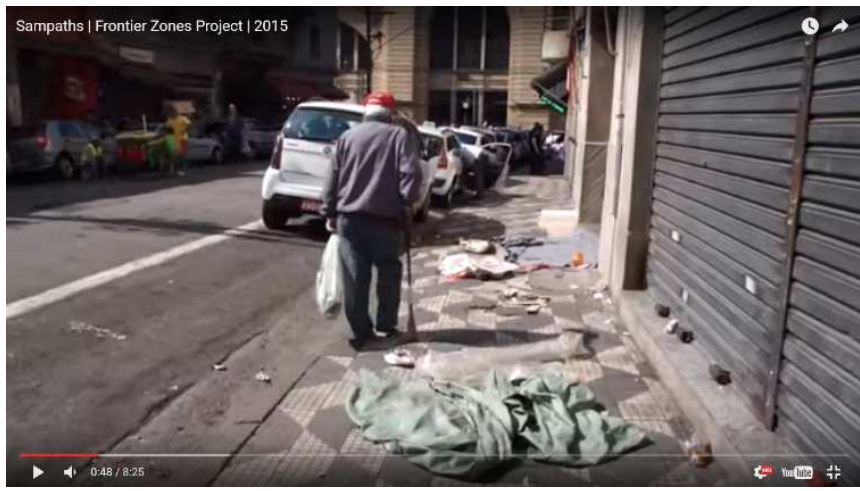

Figure 3: Obstacles on sidewalk, garbage, risk of accident for disabled man; sequence 0:48

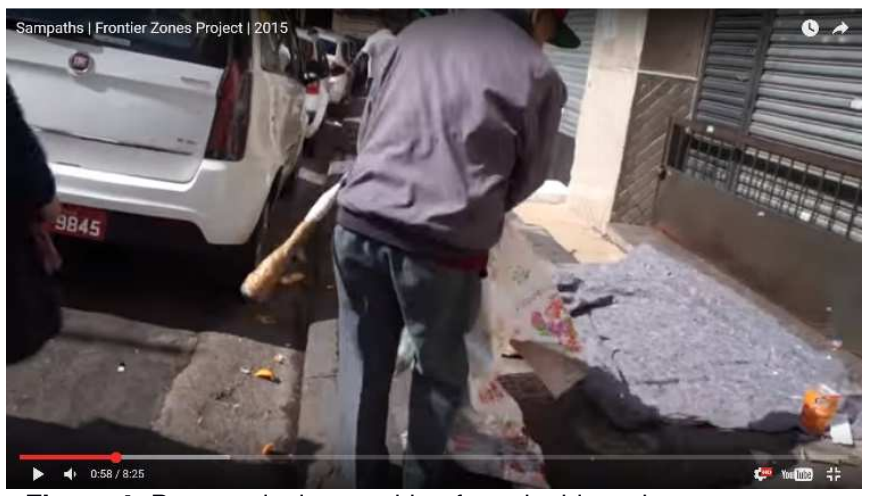

Figure 4: Protagonist is searching for valuables, shows no respect for stranger who appropriated the space; sequence 0:58 
While the scene in Figure 2 describes a situation in which the place to sleep in a public space is the center of attention, adding the previous and subsequent image forces the viewer to contemplate other complementary urban topics. Questions arise regarding garbage in public spaces, obstructions on sidewalks, the possessions of the homeless and appropriation of public space. The students describe the scene like this: "'Sam' meanders through the streets where many others are hurrying to get somewhere else. For him, the journey is the destination: He might find useful items anywhere. So for him the public space 'street' is the place where he resides, where he earns his daily bread."

Addressing items 3 and 4, "potential connections; consulting another sequence ..., development of additional interpretations and variations," the students sought analog places and protagonists in Germany. A comparable situation is people who collect returnable bottles in public spaces in Germany. To maintain human dignity, a scene was reenacted in downtown Lüneburg to then draw a comparison to the protagonists (appropriation of the property of others, garbage as a symbol of frontiers, individual pace).

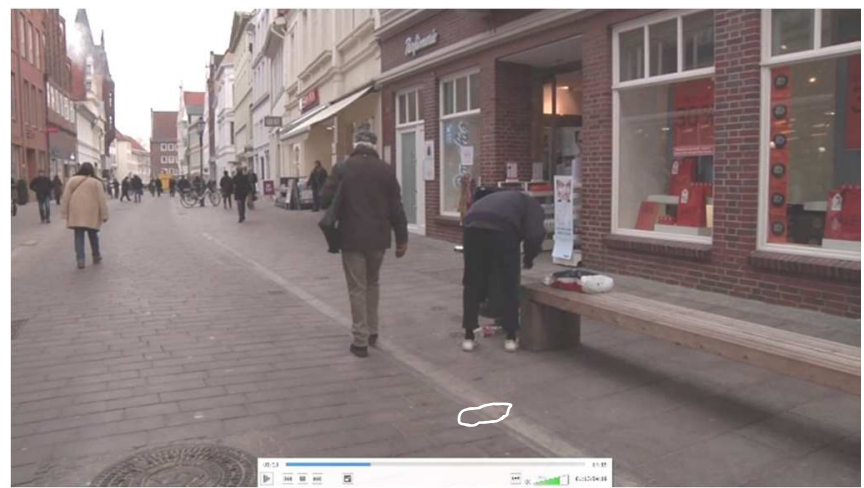

Figure 5: Protagonist finding returnable bottles, while searching for valuables; sequence 1:13

When looking for a comparable way to make money in Germany, everyone thinks of collecting returnable bottles. (The deposit for each bottle is between 7 and 25 cents.) There is not really any other place to find the urbanistic topics described above. The space appears almost sterile. And because the passersby are wearing jackets, it is obviously cold and the space is merely transitory for everyone else. The street space is the protagonist's workplace in both cases.

The following scenes are from film no. 3. "Greylight." The assumption is that this middle-aged woman is selling coffee in the early morning. The word "Café" can be seen on the column. The woman may have sprayed the word on the column herself, which leads to the assumption that she peddles coffee here regularly. How her business works is not apparent: e.g. from where does she get new coffee, or does she stay only until the coffee she brought with her is sold out. Whether this stand is legal and whether it offers the vendor protection or a place to sit down is not evident.

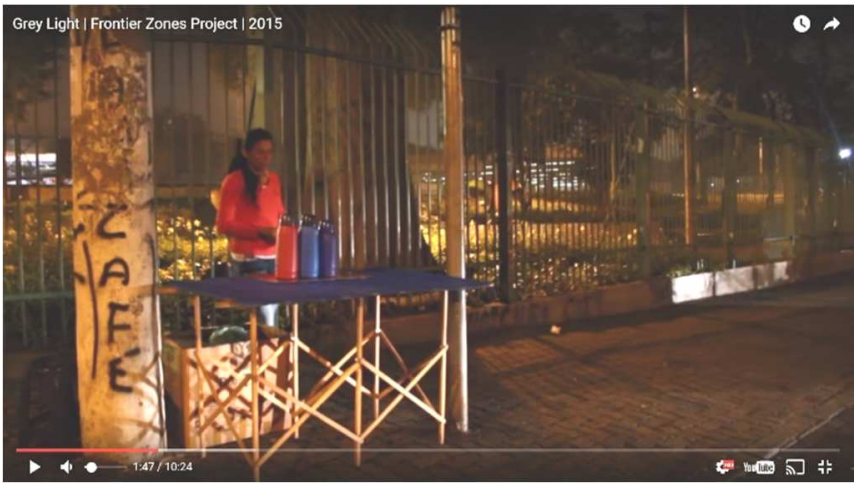

Figure 6: Street vendor, mobile coffee stand; sequence 1:47

The scenes in Figures 7 and 8 are of a street with a multitude of small shops, showing the businesses being set up for the day. The persons working here come from a social background of the gainfully employed. After sunrise, the same people assume the role of vendor. In the progression of street stalls, the street vendor has the inferior stand.

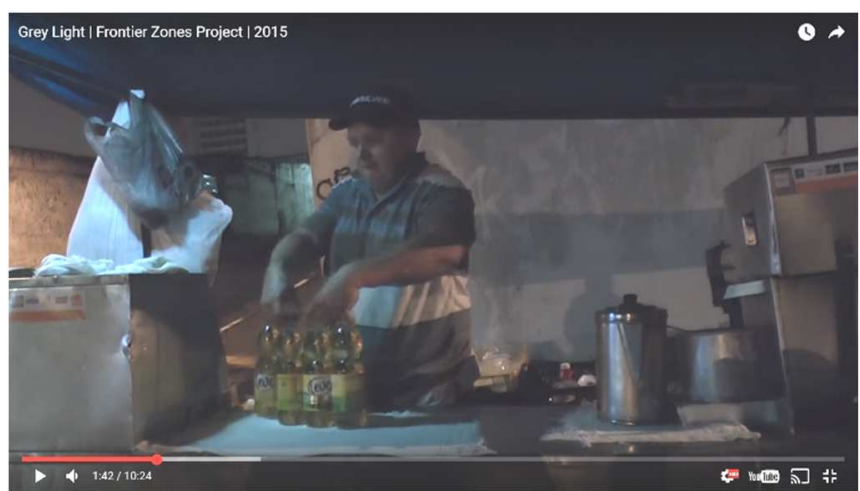

Figure 7: Opening and setting up a shop for street sale; sequence $1: 42$

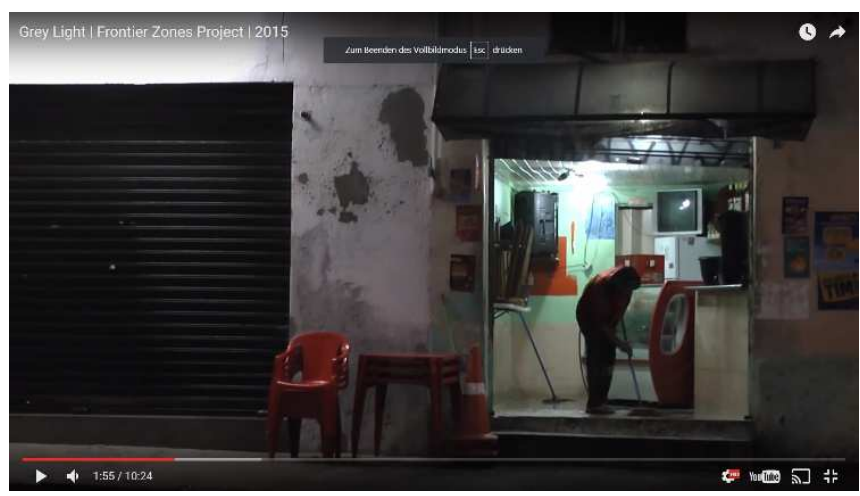

Figure 8: right: a store opening up; left: store still closed; sequence $1: 55$

The students in Germany attempted to capture the awakening along the Reeperbahn Hamburg and used early-morning deliveries to present an analog scene. The still deserted street is used to get work done to the greatest extent possible without being seen and without infringing any more than necessary on the utilization of public space. These laborers are invisible to the "normal" working population. The strict division of labor segregates the working population - something that cannot be identified in the scenes shot in São Paulo. 


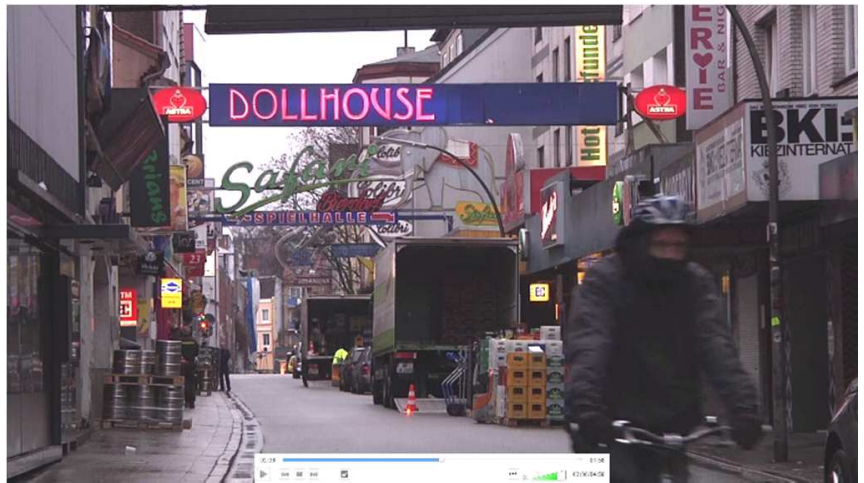

Figure 9: Deliveries near to the Reeperbahn in Hamburg; sequence 2:38

The next step was to show Brazilian life in São Paulo in an informal settlement (favela), framed by the high rises of the formal city. The atmosphere of the settlement appears almost cozy in comparison to the anonymous big city peering from above at those "down there." The spatial boundary is identical to the social and economic boundaries. Looking at other scenes offers insight into daily life in the settlement: children playing on the street, people getting their hair cut or listening to music.

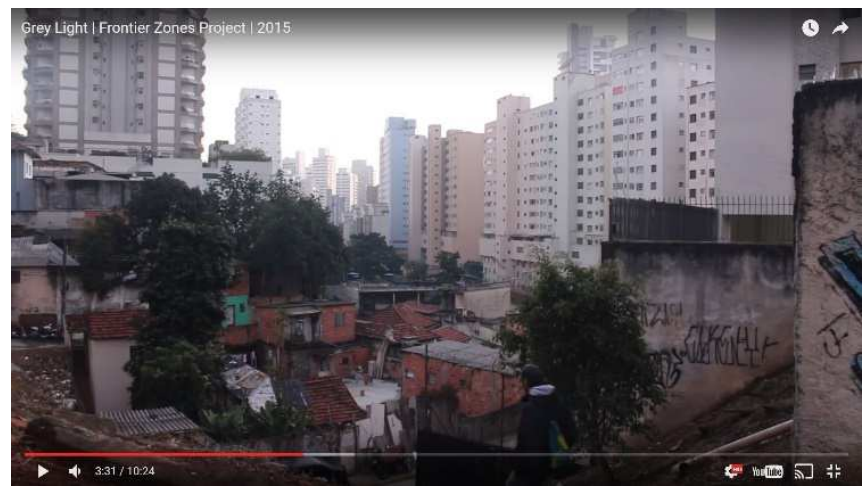

Figure 10: Favela in the foreground, surrounded by high rises; sequence $3: 31$

One does not find informal construction of residences in Germany in the way that it is present in many places throughout South America, but the homeless still appropriate space in public spaces. Because it offers protection from rain, the space under bridges is often used to establish permanent camps. The group camp shown here is centrally located and is normally visible only from passing vehicles. There are very few pedestrians and the traffic noise is substantial. Persons of meager means are alienated from the rest of the population. As in Brazil, the mood is cozy sometimes, like when music can be heard.

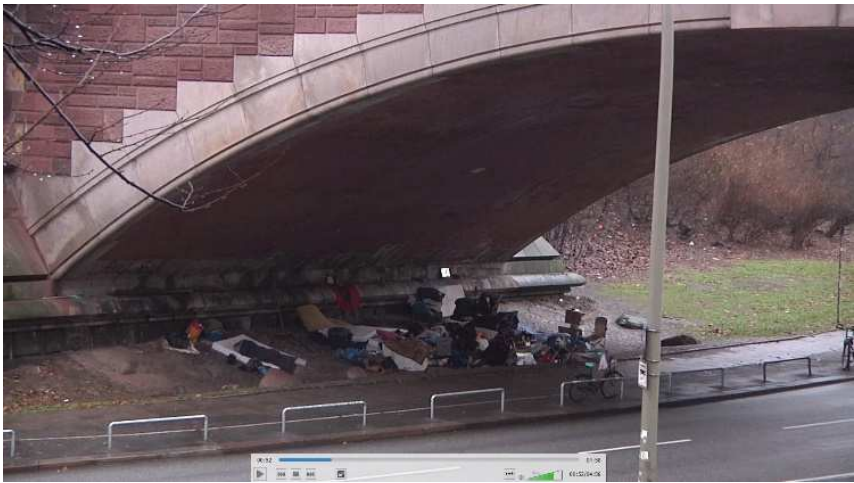

Figure 11: Homeless camp under the Kersten-Miles Bridge near the Reeperbahn, Hamburg; sequence 3:45

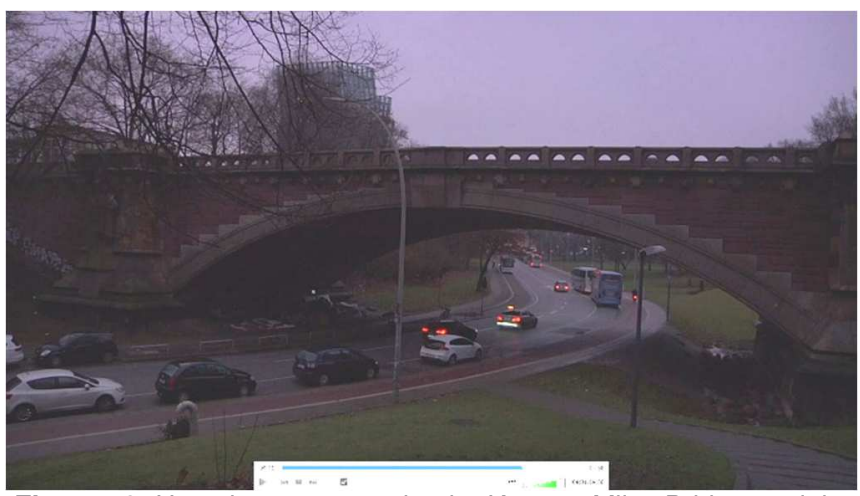

Figure 12: Homeless camp under the Kersten-Miles Bridge at night, with the "dancing towers" (high rises) along the Reeperbahn visible in the distance; sequence 4:01

\section{Conclusion}

The objective was to determine the potential of documentaries - meaning stepping into the reality of the people of São Paulo and Hamburg, using film as the method, from finding material through production and all the way to post-production. We superficially follow how people move in space and scrutinize their actions. The frontier zones do not become apparent until the sequences are stopped, the other sequences analyzed, and subsequent possibilities and ways that individual scenes may be transposed to another cultural space are contemplated. Looking for the same thing in such vastly different cultural spaces underlines the difference is many ways. Because of the low-threshold access of the medium (price, user-friendly technology), film was deemed the suitable method to be used by interdisciplinary groups attempting to clearly demonstrate the complexity of frontier zones as well the economic, climate, political and societal circumstances of the cities. Each constituted boundary shows the spatial result of a chain reaction of economic and social marginalization and segregation.

The character of the documentary style is enhanced by foregoing explanatory words - images and sounds allow for everyone's own interpretations. There is no right or wrong, only a different association, view or feeling. When the change in perspective as well as perception and learning with multiple senses (vision and hearing) are added, the hermeneutic film analysis approaches a reality which still inevitably remains 
subjective, subservient to the eye and to how the film is edited. The choice of music can have an impact on emotions; it is also intended to enable the viewer to experience emotions he would not otherwise experience though. When the viewer becomes aware of the manipulation, the opportunity arises to convey to people topics that they would not otherwise notice.

The German students particularly perceive the experimental situation of the mixed methods as a challenge in which two different fields are linked: on the one hand film (documentary as a special genre) and on the other the topics of urbanism, city planning and architecture.

Past intercultural ventures initiated by our institute between Brazil and Germany were based on similar approaches. At an event dialog_dialog, an intercontinental musical dialog between two abandoned train stations was achieved. Where trains used to depart, we planned an event that sent people off on a journey as in former times. Instead of trains though, we applied Polycom technology to send musical sound and electrical waves on their way. For this intercontinental event neither language nor translation was required, like the methodology we used this time. The room, the music, the lighting and the presence of the people provided an atmosphere for interaction, which exceeded the level of communication that would have been achieved through language. The fast pace of technological progress is intertwined with the rapid development of global networks extending throughout the entire world. New interactive structures and relationships create a new dimension of intercultural communication, which seems essential for the organization and implementation of global processes. Exchange and communication are primarily based on mutual understanding.

(Kirschner,

2013)

After we uploaded our films in the Facebook group "Frontier Zones", a Brazilian Summer School student posted that she found the dialog between Brazilian and German films and contexts to be very fertile for the creative process. She saw it as a path to understanding and to approaching different realities in their differences and similarities. (Martins, 2016)

\section{Acknowledgments}

I would like to thank the team of teachers and students of the International Summer School "Frontier Zone," 2015 São Paulo and Prof. Dr. Regine Herbrik as well as the students of the seminar "Grenzzonen in São Paulo," 2016 Leuphana University Lüneburg.

\section{References}

Böhme G. (2006), Architektur und Atmosphäre, München
Herbrik
$\mathrm{R}$.
Hermeneutische
Wissenssoziologie
(sozialwissenschaftliche Hermeneutik). Das Beispiel der kommunikativen Konstruktion normativer, sozialer Fiktionen, wie z. B. „Nachhaltigkeit“ oder: Es könnte auch immer anders sein. Distributed in: Akremi, Leila; Baur, Nina; Knoblauch, Hubert; Traue, Boris (in progress): Interpretativ Forschen. Ein Handbuch für die Sozialwissenschaften. Weinheim: Juventa.
Horwitz, Matthias; Joerges, Bernward; Potthast, Jörg (Hrsg.) (1996) Stadt und Film. Versuch zu einer "Visuellen
Soziologie“.Discussion Paper FS-II 96-503.

Wissenschaftszentrum

URL: http://bibliothek.wz-berlin.de/pdf/1996/ii96-503.pdf

Calijuri Hamra, J. E., Oliveira de V., Pratschke Tramontano, A., Wolf C., (2015), 2, 3, 4, Screenshot from the documentary "Sampath" from the International Summer School "Frontier Zones", São Paulo. Published on, http://www.leuphana.de/universitaet/personen/ursulakirschner/forschung-projekte.html

Furlan, C., Pena J.,, Marques A. C., Roca L., (2015), Figure 6, 7, 8, 10 Screenshot from the documentary "Greylight" from the International Summer School "Frontier Zones", São Paulo, Published http://www.leuphana.de/universitaet/personen/ursulakirschner/forschung-projekte.html

Gooß, A., Harley, L., Nixdorf, L., Willbränder, L., Zimmer, L., (2016) Figure 9, 11, 12 Screenshot from the documentary "Greylight" from the Seminar "Grenzzonen in São Paulo", Leuphana University of Lüneburg. Published on https://www.facebook.com/groups/frontierzones/

Hauser, S., (2011) Körper, Leib und Raum. Zur Einführung. In Architekturwissen. Grundlagentexte aus den Kulturwissenschaften, Bd. 1: Zur Ästhetik des sozialen Raumes, (Eds) Hauser, S., Kamleithner, C., Meyer, R., p. 192f, Bielefeld

Janich, P., Mittelstraß, J., (1973) Raum, in: Handbuch philosophischer Grundbegriffe, (Eds) Krings, H., Michael, H., Baumgartner, Wild, C., pp. 1154-1168., München

Jullien, F., (2009) Das Universelle, das Einförmige, das Gemeinsame und der Dialog zwischen den Kulturen. Merve Verlag Berlin.

Kirschner, U. (2013). The Use of Media in Intercultural Dialogue "dialogo_dialog". Investigation of a Research Event in Terms of Communication without Language. In Y. Luo (Eds) Cooperative Design, Visualization, and Engineering: 10th Internation Conference, CDVE 2013, Alcudia, Mallorca, Spain, Proceedings. Springer Verlag, 35-42

Kirschner, U. (2013) Figure 1

Martins, M. (2016) notice on facebook. Retrieved from https://www.facebook.com/groups/frontierzones/

Rohr R. in Psychology Today (c) 1991-2017 Sussex Publishers, LLC. Retrieved from https://www.psychologytoday.com/blog/thecreativity-cure/201306/creativity-and-the-liminal-space

Fröhlich, A., Martinez, M. Weitzenegger, F., Screenshot (2016), Figure 5 , from the documentary "Sampath" from the Seminar "Grenzzonen in São Paulo", Leuphana University of Lüneburg. Published on https://www.facebook.com/groups/frontierzones/

Schlögel, K. (2009), Im Raum lesen wir die Zeit, Carl Hanser Verlag München 